\title{
The activity of the renin-angiotensin-aldosterone system before and during submaximal bicycle exercise in relation to circulatory catecholamines in patients with Type 1 (insulin-dependent) diabetes mellitus
}

\author{
G. Sundkvist ${ }^{1}$, B. Bergström ${ }^{1}$, M. Bramnert ${ }^{2}$, B. Lilja $^{3}$ and P.Manhem ${ }^{2}$ \\ Departments of ${ }^{1}$ Medicine, ${ }^{2}$ Endocrinology, and ${ }^{3}$ Clinical Physiology, University of Lund, Malmö General Hospital, Malmö, Sweden
}

\begin{abstract}
Summary. To evaluate the renin-angiotensin-aldosterone system in relation to circulatory catecholamines, we determined renin activity, angiotensin II, aldosterone, adrenaline, and noradrenaline in plasma before and during a submaximal bicycle exercise test in 23 Type 1 (insulin-dependent) diabetic patients (aged 19-57 years, mean 37; duration of diabetes 2-32 years, mean 16), 17 with signs of cardiac autonomic neuropathy, and in 18 healthy non-diabetic subjects (aged 24-41 years, mean 29). At rest, Type 1 diabetic patients showed significantly lower aldosterone values than control subjects $(0.14 \pm 0.02 \mathrm{nmol} / 1$ and $0.22 \pm 0.02 \mathrm{nmol} / 1 ; p<0.01)$ while renin activity $\left(1.0 \pm 0.1 \mathrm{nmol} \cdot l^{-1} \cdot \mathbf{h}^{-1}\right.$ and $0.9 \pm$ $\left.0.1 \mathrm{nmol} \cdot 1^{-1} \cdot \mathrm{h}^{-1}\right)$ and angiotensin II $(14 \pm 1 \mathrm{nmol} / \mathrm{l}$ and $18 \pm$ $2 \mathrm{nmol} / \mathrm{l}) \mathrm{did}$ not differ significantly between patients and control subjects. During exercise, increments (increase from the resting value to the value at $80 \%$ of maximal working capacity) in renin $\left(1.5 \pm 0.4 \mathrm{nmol} \cdot \mathrm{l}^{-1} \cdot \mathrm{h}^{-1}\right.$ and $3.7 \pm 0.5 \mathrm{nmol} \cdot \mathrm{l}^{-1}$ $\left.\cdot \mathrm{h}^{-1} ; p<0.001\right)$, angiotensin II $(28 \pm 8 \mathrm{nmol} / 1$ and $60 \pm$ $8 \mathrm{nmol} / 1 ; p<0.01)$, aldosterone $(0.16 \pm 0.04 \mathrm{nmol} / 1$ and $0.25 \pm 0.05 \mathrm{nmol} / \mathrm{l} ; p<0.05)$, adrenaline $(1.96 \pm 0.49 \mathrm{nmol} / 1$
\end{abstract}

and $2.92 \pm 0.51 \mathrm{nmol} / \mathrm{l} ; p<0.05)$, and noradrenaline (12.01 \pm $1.25 \mathrm{nmol} / \mathrm{l}$ and $18.74 \pm 1.45 \mathrm{nmol} / \mathrm{l} ; p<0.01)$ were significantly lower in the patients than in control subjects. There was no difference in the renin-angiotensin-aldosterone response to exercise between patients with and without cardiac autonomic neuropathy but the impaired catecholamine reaction was confined to patients with cardiac autonomic neuropathy. In conclusion, Type 1 diabetic patients demonstrated low resting plasma aldosterone and reduced increments in renin activity, angiotensin II, aldosterone, and catecholamines during exercise. The low aldosterone values might be related to dysfunction of adrenal zona glomerulosa cells while it is unlikely that the reduced response to exercise of the renin-angiotensin-aldosterone system simply reflects sympathetic nerve failure.

Key words: Type 1 (insulin-dependent) diabetes mellitus, renin activity, angiotensin II, aldosterone, adrenaline, noradrenaline, catecholamines, sympathetic nerve function, autonomic neuropathy.
The renin-angiotensin-aldosterone-system is important for the regulation of vascular tone and sodium balance. Studies of the renin-angiotensin-aldosterone system in uncomplicated Type 1 (insulin-dependent) diabetic patients have shown that plasma renin activity [1-3] and plasma aldosterone concentration $[1,3,4]$ are normal and plasma angiotensin II normal [4] to low [3] in the supine position. On the other hand, in the standing position, renin activity is low in Type 1 diabetic patients with postural hypotension [5]. Although partially related to co-existing nephropathy [6], this suggests that low renin activity might be a feature of autonomic neuropathy. The objective of this study was to evaluate the renin-angiotensin-aldosterone system in relation to circulatory catecholamines at rest and after stimulated sympathetic nerve activity at submaximal bicycle exercise in Type 1 diabetic patients with and without cardiac autonomic neuropathy.

\section{Subjects and methods}

\section{Patients}

From a previous study [7] of Type 1 diabetic patients, in whom the presence of cardiac autonomic neuropathy had been assessed by the heart rate reactions to deep breathing (Expiration/Inspiration ratio $=\mathrm{E} / \mathrm{I}$ ) [8] and to tilt (acceleration and brake indices) [9] we invited 38 patients to join the present study and 27 ( 8 females) were interested in participating. Four patients, one on a selective betablocker, one on an angiotensin converting enzyme inhibitor, and two patients with hypoglycaemia (blood glucose $<4 \mathrm{mmol} / \mathrm{l}$ ) before exercise were excluded. Without other pharmacological treatment than insulin, 23 patients, of whom 17 showed cardiac autonomic neuropathy i. e. at least one autonomic neuropathy index $1.5 \mathrm{SD}$ below the age-related reference values for the $\mathrm{E} / \mathrm{I}$ ratio, acceleration index, and/or the brake index [7], participated in this study. The previous study [7] was carried out 18 to 24 months before the exercise test. However, 18 to 24 months after the exercise test, as a part of a prospective study that will be reported elsewhere, 21 of the Type 1 diabetic pa- 
Table 1. Plasma renin activity, angiotensin II, aldosterone concentration, and catecholamines in patients and in control subjects at rest and during $80 \%$ of maximal work capacity. Mean \pm SEM. Absence of superscript indicates no significant difference

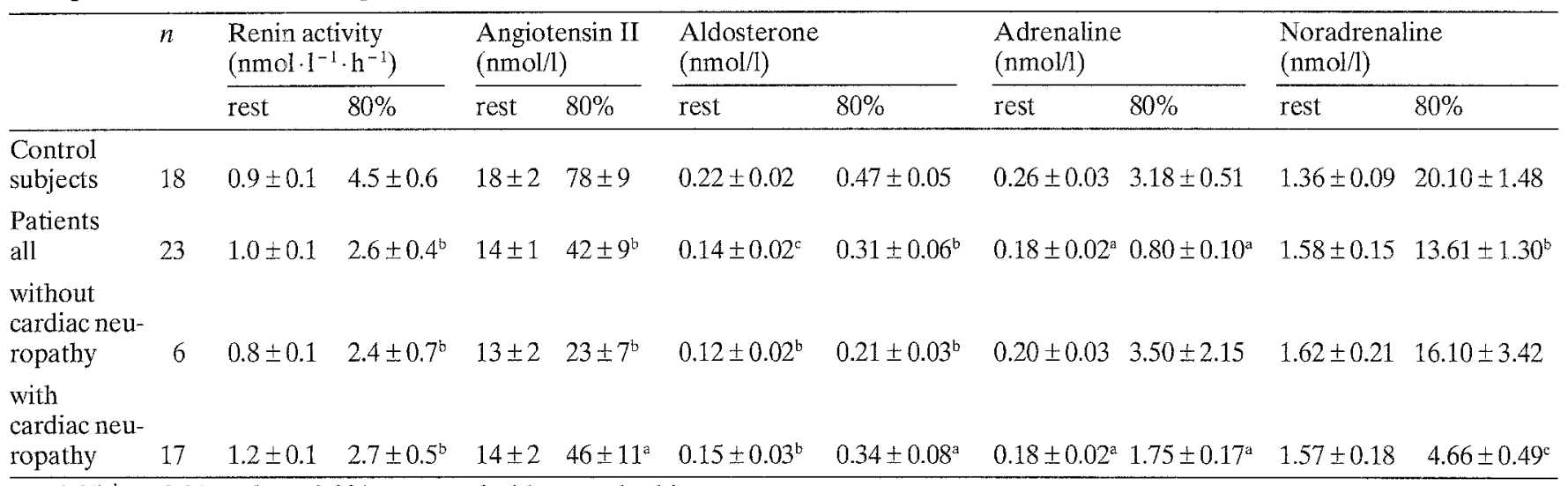

${ }^{\mathrm{a}} p<0.05,{ }^{\mathrm{b}} p<0.01$, and ${ }^{\mathrm{c}} p<0.001$ compared with control subjects

tients were re-evaluated and it was found that the autonomic nerve test results were concordant in 17 patients, an abnormal brake index had returned to normal in three patients, and an abnormal E/I ratio had returned to normal in one patient. The mean age in the 23 patients participating in the present study was $37 \pm 2$ years (mean \pm SEM) (range 19-57 years), the mean duration of diabetes $16 \pm 2$ years (range 2-32 years), mean systolic blood pressure $123 \pm 3 \mathrm{mmHg}$ (range $100-160 \mathrm{mmHg}$ ), and mean diastolic blood pressure $75 \pm 2 \mathrm{~mm} \mathrm{Hg}$ (range $60-90 \mathrm{~mm} \mathrm{Hg}$ ). Fundus photography showed retinopathy in ten of the patients (one demonstrated proliferative retinopathy) and albuminuria as shown from positive Albustix (Bayer $A G$, Leverkusen, FRG) reactions occurred in five patients.

\section{Control subjects}

From previous studies with identical design as the present [10,11], 18 healthy subjects (age 29 1 years, range 24-41 years; systolic blood pressure $128 \pm 3 \mathrm{~mm} \mathrm{Hg}$, range $95-145 \mathrm{~mm} \mathrm{Hg}$; diastolic blood pressure $81 \pm 2 \mathrm{~mm} \mathrm{Hg}$, range $60-95 \mathrm{~mm} \mathrm{Hg}$ ), acted as controls in the exercise test. Control subjects were slightly younger $(p<0.01)$ than the diabetic patients. The study was approved by the Ethical Committee of the Medical Faculty, University of Lund. Informed consent was obtained from all subjects.

\section{Exercise test}

The maximal working capacity (MWC) was determined in each subject using a bicycle ergometer. The initial work load was $50 \mathrm{Watt}(\mathrm{W})$. The load was increased $10 \mathrm{~W}$ each min until exhaustion [12]. Basedon the individual MWC, a submaximal work test was carried out at least 4 days later. On that day, the patient took his regular morning dose of insulin. Both patients and control subjects had their regular breakfast on 07.00 hours. At 09.00 hours, the patient arrived at the laboratory and a catheter (Venflon, Viggo, Helsingborg, Sweden) was inserted into an antecubital vein and kept patent by a slow sodium chloride infusion. Thereafter, the patient rested in the supine position for $30 \mathrm{~min}$ and then was seated on the ergometer bicycle for another $10 \mathrm{~min}$. After that, the patient started to exercise with $50 \%$ of MWC for $10 \mathrm{~min}$ immediately followed by $80 \%$ of MWC for another $10 \mathrm{~min}$. Blood samples were collected after the 25 th min of supine rest, during the last min of $50 \%$ of MWC, and during the last min of $80 \%$ of MWC. One patient was unable to continue beyond $1 \mathrm{~min}$ of $80 \% \mathrm{MWC}$ and no blood samples were obtained at $80 \%$ MWC.

\section{Analytical methods}

Blood glucose was determined by a routine hexokinase method. Samples for hormone analysis were put on ice and immediately centrifuged, plasma separated, and stored at $-20^{\circ}$ until assayed. All samples from one individual were analysed in one assay run. All hormone analyses have previously been described in detail [13]. Renin activity was determined as the amount of the angiotensin I generated during one $\mathrm{h}$ incubation at $\mathrm{pH} 6.0$ (variation coefficient $=8 \%$; sensitivity $0.02 \mathrm{nmol} \cdot \mathrm{l}^{-1} \cdot \mathrm{h}^{-1}$ ), angiotensin II was extracted on Dovex AG $50 \mathrm{~W}-2$ resin and determined by RIA (variation coefficient $=8 \%$; sensitivity $1.6 \mathrm{nmol} / \mathrm{l}$ ), plasma aldosterone was determined by RIA (variation coefficient $=5 \%$; sensitivity $0.08 \mathrm{nmol} / 1$ ), and plasma catecholamines were assessed by a radioenzymatic method (variation coefficient $=15 \%$ and sensitivity $0.07 \mathrm{nmol} / 1$ for adrenaline; variation coefficient $16 \%$ and sensitivity $0.18 \mathrm{nmol} / \mathrm{l}$ for noradrenaline).

\section{Statistical analysis}

Two-tailed non-parameteric Mann-Whitney $U$ test was employed in group comparisons and $p<0.05$ was considered significant. The Spearman rank correlation test was used for determination of $r$ values. Values are given as mean \pm SEM.

\section{Results}

\section{All patients}

Renin-angiotensin-aldosterone system. Before exercise, plasma renin activity and plasma angiotensin II did not differ significantly between patients and control subjects while plasma aldosterone was significantly $(p<0.001)$ lower in the patients (Table 1). During $80 \%$ of MWC, renin activity, angiotensin II, and aldosterone were significantly $(p<0.01)$ lower in patients than in control subjects. In addition, increments $(\Delta 80 \%=$ difference between basal and $80 \%$ of MWC) in renin activity $\left(1.5 \pm 0.4 \mathrm{nmol} \cdot \mathrm{l}^{-1} \cdot \mathrm{h}^{-1} \quad\right.$ and $3.7 \pm 0.5 \mathrm{nmol} \cdot \mathrm{l}^{-1} \cdot \mathrm{h}^{-1}$ $p<0.001)$, angiotensin II $(28 \pm 8 \mathrm{nmol} / \mathrm{l}$ and $60 \pm 8 \mathrm{nmol} / \mathrm{l}$; $p<0.01)$, and aldosterone $(0.16 \pm 0.04 \mathrm{nmol} / \mathrm{l}$ and $0.25 \pm 0.05 \mathrm{nmol} / 1 ; p<0.05)$ were significantly lower during exercise in patients than in control subjects. There were no significant correlations between the duration of diabetes and renin activity $(r=0.07)$, angiotensin II $(r=0.04)$, or aldosterone $(r=-0.30)$ before exercise.

Catecholamines. Before exercise, plasma adrenaline, but not noradrenaline, was slightly lower $(p<0.05)$ in patients than in control subjects while during exercise adrenaline 
$(p<0.05)$ and plasma noradrenaline $(p<0.01)$ were significantly lower in the patients (Table 1). Moreover, increments $(\Delta 80 \%)$ in adrenaline $(1.96 \pm 0.49 \mathrm{nmol} / \mathrm{l}$ and $2.92 \pm 0.51 \mathrm{nmol} / \mathrm{l} ; p<0.05)$ and noradrenaline $12.01 \pm$ $1.25 \mathrm{nmol} / \mathrm{l}$ and $18.74 \pm 1.45 \mathrm{nmol} / \mathrm{l} ; p<0.01)$ were significantly lower during exercise in patients than in control subjects. There were no significant correlations between the duration of diabetes and adrenaline $(r=0.01)$ or noradrenaline $(r=0.28)$ before exercise.

\section{Patients with cardiac autonomic neuropathy}

The 17 patients with cardiac autonomic neuropathy demonstrated no significant differences in age and duration of diabetes in comparison to the six patients without cardiac autonomic neuropathy (age $35 \pm 2$ years vs $40 \pm 4$ years and duration $15 \pm 2$ years vs $17 \pm 4$ years, respectively). Similarly, mean supine blood pressures did not differ significantly between patients with and without cardiac autonomic neuropathy $(120 / 74 \pm 4 / 2 \mathrm{~mm} \mathrm{Hg}$ and $132 / 79 \pm$ $8 / 3 \mathrm{~mm} \mathrm{Hg}$ ).

Renin-angiotensin-aldosterone system. Table 1 shows that there were no major differences between patients with and without cardiac autonomic neuropathy with respect to renin activity, angiotensin II, and aldosterone before and during exercise.

Catecholamines. Compared with control subjects, patients with cardiac autonomic neuropathy showed significantly lower adrenaline before exercise as well as adrenaline and noradrenaline at $80 \%$ of MWC (Table 1). In addition, increments $(\triangle 80 \%)$ during exercise in adrenaline $(1.57 \pm 0.17 \mathrm{nmol} / 1$ and $2.92 \pm 0.51 \mathrm{nmol} / 1 ; p<0.05)$ and noradrenaline $(11.31 \pm 1.33 \mathrm{nmol} / \mathrm{l}$ and $18.74 \pm$ $1.45 \mathrm{nmol} / 1 ; p<0.001$ ) were significantly lower in patients with cardiac autonomic neuropathy than in control subjects.

\section{Discussion}

\section{Pre-exercise}

In this study, patients with a moderately long duration of Type 1 diabetes showed a supine renin activity that did not differ from control subjects confirming previous findings in uncomplicated patients [1-3]. Concerning angiotensin II levels, there are few reports. Normal levels [4], as in our study, as well as low angiotensin II in combination with normal to elevated angiotensin converting enzyme activity have been reported [3] in uncomplicated Type 1 diabetic patients. It was remarkable that supine, resting, plasma aldosterone was low despite normal renin activity and angiotensin II in the Type 1 diabetic patients of the present study.

In diabetic patients with advanced nephropathy, low aldosterone has been demonstrated $[14,15]$ but in the present study nephropathy was rare and cannot explain the finding of low aldosterone. Normal aldosterone has previously been observed in uncomplicated Type 1 diabetic patients $[3,4]$. The low aldosterone levels in the patients of our study might reflect differences in the duration of diabetes; 16 years in this study and 7 years in the previous [4]. However, the lack of a significant correlation between the duration of diabetes and the aldosterone concentration in our as well as in the previous study [4] does not support this assumption. It is unlikely, that differences in age between patients and control subjects affected the aldosterone results. Certainly, a negative correlation between age and aldosterone has been described by some [16-18], though not all [4], investigators. The found differences in aldosterone between patients and control subjects are too large to be attributed to age only; plasma aldosterone diminishes with less than $10 \%$ over a 7 year period [17], with about $25 \%$ after a 40 year period [16], and urine aldosterone was unchanged when non-diabetic subjects with an age difference of 30 years were compared [18]. Moreover, renin activity, which may show a negative association with age $[17,18]$ did not differ between patients and control subjects in our study. Furthermore, the potential stimulation of aldosterone secretion by the renin-angiotensin system was equal in patients and control subjects and cannot explain the low aldosterone levels in the patients.

A decreased aldosterone production by adrenal glomerulosa cells after angiotensin II stimulation has been described in diabetic rats [19]. In analogy, an impaired zona glomerulosa cell function may exist in Type 1 diabetic patients and subnormal angiotensin II receptor numbers have been reported [20], though recently questioned [21], in the platelets of Type 1 diabetic patients. The observation of adrenal medullary antibodies in Type 1 diabetic patients indicates that immunological factors might alter adrenaline secretion [22]. Immunological factors might also affect zona glomerulosa cells and not only chromaffin cells in the adrenal gland.

\section{Exercise}

During exercise the increments in renin activity, angiotensin II, and aldosterone were lower in patients than in control subjects. Further, increments in catecholamines were reduced in the patients during exercise indicating a disturbance of the sympatho-adrenal system; the work-load and the degree of stress were similar in patients and control subjects. Sympatho-adrenal dysfunction is not rare in Type 1 diabetic patients with a duration of diabetes of more than 10 years $[23,24]$ i.e. corresponding to that noted in the patients of the present study. The disturbance in renin-angiotensin-aldosterone system during exercise might well be related to a decreased activity of the sympatho-adrenal system. In agreement with this, patients with cardiac neuropathy showing lower increments in catecholamines than control subjects, displayed an impaired renin-angiotensin-aldosterone reaction during exercise. However, the six patients without signs of cardiac autonomic neuropathy and with increments in catecholamines during exercise not significantly different from the control subjects showed low increments in renin 
activity, angiotensin II, and aldosterone as did patients with cardiac autonomic neuropathy. Although the content of catecholamines in vascular wall decreases with the duration of Type 1 diabetes [25] and employed cardiac autonomic neuropathy tests evaluate parasympathetic nerve function and not only sympathetic nerve function $[8,9,24]$, our finding in patients without cardiac autonomic neuropathy makes it unlikely that proved impairments in renin-angiotensin-aldosterone system during exercise simply reflected sympathetic nerve dysfunction. Thus, the reason for the reduced activity of the renin-angiotensin-aldosterone system during exercise has to be further elucidated. The possibility that the abnormality reflects an intra-renal beta-adrenergic receptor defect impairing the renin secretion as suggested from previous experiments in diabetic patients [26] has to be seriously considered.

In conclusion, patients with Type 1 diabetes of moderate duration show low supine, resting, plasma aldosterone levels despite normal renin activity and normal angiotensin II levels. The reason for this finding is unclear, but a dysfunction of adrenal zona glomerulosa cells with reduced aldosterone secretion might be responsible. During exercise, Type 1 diabetic patients show reduced responses in the activity of the renin-angiotensin-aldosterone system which might be a consequence of sympathetic dysfunction but the study suggests that other factors also are of importance.

Acknowledgements. We thank Ms. K. Rosberg for skillful assistance in the performance of the exercise tests and Mr. T. Borge for expert hormone analysis. This work was supported by grants from Lundström Foundation, Svenska Diabetesförbundet, University Funds, and Funds from the Malmö General Hospital.

\section{References}

1. Moss S, Oster JR, Perez GO, Katz FH, Vaamonde CA (1978) Renin-aldosterone responsiveness in uncomplicated juveniletype diabetes mellitus. Horm Res 9: 130-136

2. Drury PL, Bodansky HJ, Oddie CJ, Edwards CRW (1984) Factors in the control of plasma renin activity and concentration in Type 1 (insulin-dependent) diabetes. Clin Endocrinol 20: 607618

3. Feldt-Rasmussen B, Mathiesen ER, Deckert T, Giese J, Christensen NJ, Bent-Hansen L, Nielsen MD (1987) Central role for sodium in the pathogenesis of blood pressure changes independent of angiotensin, aldosterone and catecholamines in Type 1 (insulin-dependent) diabetes mellitus. Diabetologia 30: 610-617

4. Ferriss JB, Sullivan PA, Gonggrijp H, Cole M, O'Sullivan DJ (1982) Plasma angiotensin II and aldosterone in unselected diabetic patients. Clin Endocrinol 17:261-269

5. Christlieb AR, Munichoodappa C, Braaten JT (1974) Decreased response of plasma renin activity to orthostasis in diabetic patients with orthostatic hypotension. Diabetes 23: 835840

6. O'Hare JA, Ferriss JB, Twomey B, Brady D, O'Sullivan DJ (1986) Diabetic orthostatic hypotension: the role of total exchangeable sodium and nephropathy. Diab Res 3: 301-306

7. Bergström B, Lilja B, Österlin S, Sundkvist G (1987) Autonomic neuropathy in type I diabetes: influence of duration and other diabetic complications. Acta Med Scand 222: 147-154
8. Sundkvist G, Almér L-O, Lilja B (1979) Respiratory influence on heart rate in diabetes mellitus. Br Med J 1: 924-925

9. Sundkvist G, Lilja B, Almér L-O (1980) Abnormal diastolic blood pressure and heart rate reactions to tilting in diabetes mellitus. Diabetologia 19: 433-438

10. Bramnert M, Hökfelt B (1985) Lack of effect of naloxone in a moderate dosage on the exercise-induced increase in blood pressure, heart rate, plasma catecholamines, plasma renin activity and plasma aldosterone in healthy males. Clin Science 68: 185-191

11. Bramnert M (1988) The effect of naloxone on blood pressure, heart rate, plasma catecholamines, renin activity, and aldosterone following exercise in healthy males. Reg Peptides 22: 295301

12. Åström H, Jonsson B (1986) Design of exercise test with special reference to heart patients. Br Heart J 38: 289-296

13. Manhem P, Bramnert M, Hulthén UL, Hökfelt B (1981) The effect of captopril on catecholamines, renin activity, angiotensin II and aldosterone in plasma during physical exercise in hypertensive patients. Eur J Clin Invest 11: 389-395

14. Perez GO, Lespier L, Jacobi J, Oster JR, Katz FH, Vaamonde CA, Fishman LM (1977) Hyporeninemia and hypoaldosteronism in diabetes mellitus. Arch Intern Med 137: 852-855

15. Christlieb AR, Kaldany A, D'Elia JA, Williams GH (1978) Aldosterone responsiveness in patients with diabetes mellitus. Diabetes 27: 732-737

16. Weidmann $P$, De Myttenaere-Bursztein S, Maxwell MH, De Lima $J$ (1975) Effect of aging on plasma renin and aldosterone in normal man. Kidney Int 8:325-333

17. Zadic I, Kowarski AA (1980) Normal integrated concentration of aldosterone and plasma renin activity: effect of age. J Clin Endocrinol Met 50: 867-869

18. Noth RH, Lassman MN, Tan SY, Fernandez-Cruz A, Mulrow PJ (1977) Age and the renin-aldosterone system. Arch Intern Med 137: 1414-1417

19. Kigoshi T, Imaizumi N, Azukizawa S, Yamamoto I, Uchida K, Konishi F, Morimoto S (1986) Effects of angiotensin II, adrenocorticotropin, and potassium on aldosterone production in adrenal zona glomerulosa cells from streptozotocin-induced diabetic rats. Endocrinology 118: 183-188

20. Connell JMC, Ding Y-A, Fisher BM, Frier BM, Semple PF (1986) Reduced number of angiotensin II receptors on platelets in insulin-dependent diabetes. Clin Science 71: 217-220

21. Mann J, Ritz E (1988) Renin-angiotensin system beim diabetischen Patienten. Klin Wochenschr 66: 883-891

22. Brown FM, Kamalesh M, Adri MNS, Rabinowe SL (1988) Antiadrenal medullary antibodies in IDDM subjects and subjects at high risk of developing IDDM. Diabetes Care 11:30-33

23. Bolli G, De Feo O, Compagnucci P, Cartechini MG, Angeletti G, Santenusanio F, Brunetti P, Gerich JE (1983) Abnormal glucose counterregulation in insulin-dependent diabetes mellitus. Interaction of anti-insulin antibodies and impaired glucagon and epinephrine secretion. Diabetes 32: 134-141

24. Sundkvist G, Lilja B, Manhem P, Almér L-O (1984) Responses of plasma catecholamines to tilt in patients with diabetes mellitus. Acta Med Scand 216:223-227

25. Neubauer B, Christensen NJ (1976) Norepinephrine, epinephrine, and dopamine contents of the cardiovascular system in long-term diabetics. Diabetes 25: 6-10

26. Tuck ML, Sambhi MP, Levin L (1979) Hyporeninemic hypoaldosteroneism in diabetes mellitus. Studies of the autonomic nervous system's control of renin release. Diabetes 28: 237-241

Received: 12 May 1989

and in revised form: 28 September 1989

Dr. G. Sundkvist

Department of Medicine

University of Lund

Malmö General Hospital

S-21.401 Malmö

Sweden 